\title{
Breathing patterns in children with craniofacial dysostosis and hindbrain herniation
}

\author{
S.L. Gonsalez*, D. Thompson**, R. Hayward**, R. Lane*
}

Breathing patterns in children with craniofacial dysostosis and hindbrain herniation. S.L. Gonsalez, D. Thompson, R. Hayward, R. Lane. CERS Journals Ltd 1998.

ABSTRACT: In the past few years, hindbrain herniation has become recognized as a frequent feature of the child with syndromic craniofacial dysostosis. The clinical significance of hindbrain herniation in these disorders is unclear. Abnormalities of respiratory control have frequently been reported. The aim of the present study was to document the incidence of obstructive and central respiratory abnormalities during sleep in craniofacial syndromes with hindbrain herniation.

We performed cardiorespiratory sleep studies during unsedated night-time sleep in a group of 13 children. Hindbrain herniation was confirmed by magnetic resonance imaging (MRI) and ranged $1.5-26.9 \mathrm{~mm}$ below the cranial base.

Sleep studies revealed central respiratory pauses associated with important reduction of the arterial oxygen saturation $\left(S_{\mathrm{a}, \mathrm{O}_{2}}\right)$ in only two of 13 cases (minimum $\mathrm{Sa}_{\mathrm{a}} \mathrm{O}_{2}$ $86 \%$ and $87 \%$ ). In contrast 10 of 13 children had some degree of upper airway obstruction (four mild, three moderate and three severe). Of the remaining three children, two had previous long-term tracheostomies. Changes in the breathing pattern were proportional to the severity of the obstruction and comprised increased respiratory efforts and arterial oxygen desaturation. Infrequent mixed apnoeas were observed in five patients, and their severity reflected the severity of the obstructive component.

In conclusion, obstruction of the upper airways was the predominant sleep-related respiratory problem in this group of patients. Hindbrain herniation was not associated with a high incidence of central sleep apnoea.

Eur Respir J 1998; 11: 866-872.

Craniofacial dysostosis involves the premature and progressive fusion of the skull sutures and may affect the bones of the skull vault, cranial base and facial skeleton. The primary form of the condition occurs in approximately one in 1,000 children [1]. The nature and extent of the consequent cranial deformities are determined by the number of sutures involved, the order in which they fuse and the time at which fusion occurs. The first description of chronic hindbrain tonsillar herniation in a patient with a craniofacial syndrome was in an infant with Pfeiffer syndrome [2]; hindbrain herniation has subsequently been described in children with clover-leaf skull malformation and in Crouzon and Apert syndromes [3-6]. It has been most frequently observed in association with hydrocephalus and in individuals who have undergone craniofacial remodelling to normalize intracranial pressure [2-6]. The aetiology of the herniation is not clear. Whilst it has been considered a congenital condition, recent data have suggested that it could also be an acquired condition $[3,4,7]$. A number of mechanisms have been suggested for its aetiology; these include lumbar-peritoneal shunting, raised intracranial pressure, small posterior fossa volume and cerebral venous hypertension. The caudal displacement of cerebellar tissue through the foramen magnum and into the cervical canal may be associated with anatomical changes in the brainstem, with lesions of the cerebellum and
*Respiratory and **Craniofacial Units, Institute of Child Health and Great Ormond Street Hospital for Children NHS Trust, London, UK.

Correspondence: S. Gonsalez

Respiratory Unit

Institute of Child Health

30 Guilford Street

London

WC1N 1EH

UK

Fax: 441718298634

Keywords: Children

craniofacial dysostosis

hindbrain herniation

sleep

sleep apnoea

Received: November 211996

Accepted after revision October 271997

This study was supported by the Wellcome Trust (Grant Ref. 044343/Z/95/Z). SLG was supported in part by Portex Smith Industries. compression of the medulla. Whilst there have been reports of severe cases of Crouzon syndrome in which symptoms of hindbrain herniation included suboccipital headache, hand numbness, hyperreflexia and spastic quadriparesis [4], in many cases it is an incidental finding and not accompanied by symptoms. From the respiratory point of view, herniation of the hindbrain may potentially affect brainstem neurological structures including the ponto-medullary respiratory centres and the nuclei of the cranial nerves innervating the dilator muscles of the upper airway. Malfunction in these structures may lead to feeding difficulties, stridor, breath holding spells, upper airway obstruction and central sleep apnoea [8].

The clinical significance of hindbrain herniation in patients with craniofacial dysostosis is not clear. Because of the complexity of the craniofacial dysostosis syndromes and the nonspecific nature of respiratory manifestations of hindbrain herniation, it is possible that hindbrain herniation as a cause of respiratory problems may have passed unnoticed.

The aim of the present study was to document the incidence of both obstructive and central respiratory anomalies in these patients. This was achieved by monitoring respiratory patterns during sleep in a group of children with craniofacial syndromes, in whom hindbrain herniation had been confirmed by magnetic resonance imaging (MRI). 


\section{Subjects and methods}

\section{Subjects}

We performed cardiorespiratory sleep studies in 13 syndromic craniofacial patients recruited from the Craniofacial Unit, Great Ormond Street Hospital for Children National Health Service (NHS) Trust, in whom hindbrain herniation had been diagnosed by MRI examinations performed as part of their routine clinical craniofacial assessment. The interval between the diagnosis of hindbrain herniation and the sleep study varied between 2 days and 5.8 yrs (median 0.7 yrs); however, none of the cases had any surgical procedure performed during the intervening periods. The details of the patients are given in table 1; seven children had Crouzon syndrome, two had Apert syndrome, three had Pfeiffer syndrome and one had a clover-leaf skull malformation. Their ages ranged 0.3-11.4 yrs. Children who had had upper airway infections in the

Table 1. - Individual patient's details: age at time of study, diagnosis, extent of hindbrain herniation (measured from magnetic resonance imaging (MRI) scan) and interval between MRI scan and sleep study

\begin{tabular}{lrccl}
\hline $\begin{array}{l}\text { Patient } \\
\text { No. }\end{array}$ & $\begin{array}{c}\text { Age } \\
\text { yrs }\end{array}$ & Syndrome & $\begin{array}{c}\text { Herniation } \\
\mathrm{mm}\end{array}$ & $\begin{array}{c}\text { Interval } \\
\text { yrs }\end{array}$ \\
\hline 1 & 0.7 & Apert & 1.5 & 0.2 \\
2 & 11.0 & Crouzon & 2.5 & 0 \\
3 & 0.7 & Crouzon & 3.5 & 0.1 \\
4 & 4.8 & Crouzon & 10.5 & 0 \\
5 & 2.4 & Crouzon & 17.0 & 0.2 \\
6 & 6.3 & Clover leaf & 27.0 & 0 \\
7 & 11.4 & Pfeiffer & 3.0 & 3.6 \\
8 & 7.8 & Pfeiffer & 6.5 & 1.2 \\
9 & 3.0 & Apert & 8.0 & 2.5 \\
10 & 1.4 & Crouzon & 9.5 & 5.8 \\
11 & 1.3 & Crouzon & 11.0 & 0.7 \\
12 & 5.4 & Crouzon & 15.0 & 1.6 \\
13 & 6.3 & Pfeiffer & 26.0 & 4.3 \\
\hline
\end{tabular}

3 weeks preceding the study and those with lower respiratory tract and cardiovascular diseases were excluded from the study. The sleep studies were performed as part of the routine clinical management. Formal approval for this work was obtained from the local ethics committee and informed parental consent was obtained in all cases.

\section{Methods}

Clinical history. A detailed clinical history was taken from the parents and from the children who were old enough to contribute an account of their symptoms. The history focused upon any signs and symptoms of respiratory difficulties, particularly during sleep. A diagnosis of central respiratory problems was based upon a description of cessation of breathing movements, with or without cyanosis, in the absence of snoring or increased breathing efforts. Obstructive respiratory problems were defined in terms of a description of mouth breathing, snoring, increased breathing efforts and sleep disruption. When the parents description suggested an obstructive component, the severity was classified by the interviewer as either mild, moderate or severe, based upon our standard criteria (table 2) [9].

Measurement of hindbrain herniation. For the purposes of this study, hindbrain herniation was defined as any descent of the cerebellar tonsils below the plane of the foramen magnum, on a midline T1-weighted sagittal MRI. The ex-tent of herniation was measured in millimetres and an ex-ample is shown in figure 1.

Assessment of the respiratory patterns. In order to assess the patients' respiratory patterns, overnight cardiorespiratory sleep studies were performed during routine hospital admissions. The sleep studies comprised $4.5-10 \mathrm{~h}$ of continuous and simultaneous recording during natural sleep of the following variables: 1) rib cage and abdominal respiratory movements (uncalibrated strain gauges); 2) arterial oxygen saturation $\left(\mathrm{Sa}_{\mathrm{a}} \mathrm{O}_{2}\right.$; pulse oximetry); 3 ) electrocardiogram (ECG); 4) movement (pressure sensitive

Table 2. - Criteria used for the assessment of the severity of respiratory problems and upper airway obstruction based on parental assessment and sleep study incorporating clinical observations and objective sleep study criteria

\begin{tabular}{|c|c|c|c|}
\hline \multirow[b]{2}{*}{ Severity } & \multirow{2}{*}{$\begin{array}{l}\text { Parental assessment } \\
\text { Clinical history }\end{array}$} & \multicolumn{2}{|c|}{ Sleep study } \\
\hline & & Clinical observations & Polygraphic criteria \\
\hline Mild & $\begin{array}{l}\text { Mouth breathing } \\
\text { Slightly increased respiratory effort } \\
\text { Snoring }\end{array}$ & $\begin{array}{l}\text { Slightly increased respiratory efforts, } \\
\text { usually mouth breathing with or with- } \\
\text { out slight intercostal or suprasternal } \\
\text { inspiratory recessions, with or with- } \\
\text { out snoring, without restless sleep }\end{array}$ & $\begin{array}{l}\text { Rib-cage and abdominal signals in- } \\
\text { phase or slightly out-of-phase; } \mathrm{Sa}_{\mathrm{a}} \mathrm{O}_{2} \\
\text { within normal limits; with or without } \\
\text { few brief, mild dips in } \mathrm{S}_{\mathrm{a}, \mathrm{O}_{2}} \text { never } \\
<90 \% \text {. }\end{array}$ \\
\hline Moderate & $\begin{array}{l}\text { Noticeably increased breathing } \\
\text { difficulties } \\
\text { Minor sleep disturbance } \\
\text { Snoring }\end{array}$ & $\begin{array}{l}\text { Moderately increased respiratory } \\
\text { efforts, usually mouth breathing, with } \\
\text { or without moderate intercostal or } \\
\text { suprasternal inspiratory recession, with } \\
\text { or without "snoring" and "snorting" } \\
\text { with disrupted, restless sleep }\end{array}$ & $\begin{array}{l}\text { Rib-cage and abdominal signals out- } \\
\text { of-phase; baseline } \mathrm{S}_{\mathrm{a}, \mathrm{O}_{2}} \text { within } \\
\text { normal limits; more frequent, } \\
\text { repeated periods of desaturation to } \\
\text { about } 85 \% \text {. }\end{array}$ \\
\hline Severe & $\begin{array}{l}\text { Markedly increased breathing } \\
\text { difficulties } \\
\text { Very disrupted sleep } \\
\text { Cyanosis } \\
\text { Snoring }\end{array}$ & $\begin{array}{l}\text { Markedly increased respiratory efforts, } \\
\text { mouth breathing, marked intercostal or } \\
\text { suprasternal inspiratory indrawings, } \\
\text { with or without nasal flaring; loud } \\
\text { "snoring" and "snorting" with dis- } \\
\text { rupted, restless sleep }\end{array}$ & $\begin{array}{l}\text { Rib-cage and abdominal signals out- } \\
\text { of-phase, with frequent prolonged } \\
\text { episodes of paradoxical breathing; } \\
\text { frequent, prolonged periods of } \\
\text { arterial oxygen desaturation. }\end{array}$ \\
\hline
\end{tabular}




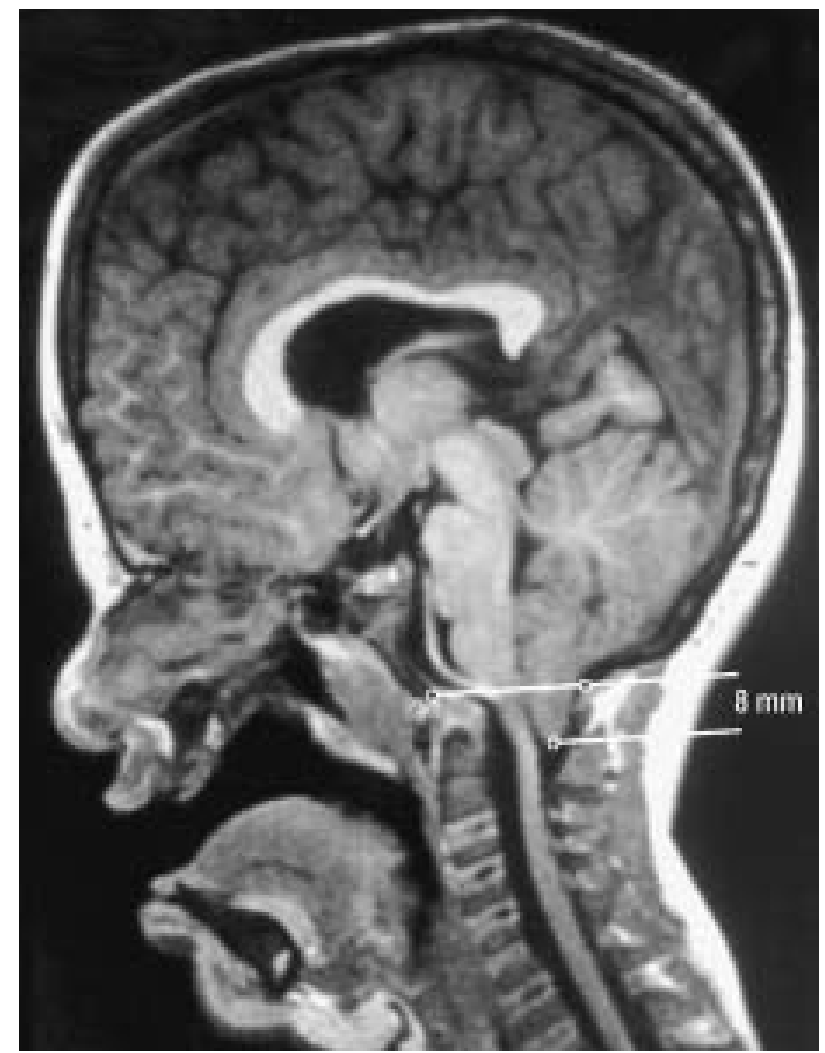

Fig. 1. - T1-weighted sagittal magnetic resonance image of a $3 \mathrm{yr}$ old girl with Apert syndrome (patient No. 9), showing herniation of the hindbrain of $8 \mathrm{~mm}$. It is also possible to observe the characteristic maxillary hypoplasia, with consequently flat midface and reduced dimensions of the upper airways.

mattress); and 5) video and sound recording. The CARDAS (Oxford, UK) computer-based sleep system was used for recording and analysing data. The same observer (SLG) was present for all studies, in order to assess the breathing patterns and record the behavioural sleep state, using standard criteria [10]. Quiet sleep (QS), which corresponds approximately to non-rapid eye movement (non-REM) deep sleep, was identified as periods during which there were no facial movements, only occasional startles and extremity movements, and breathing was regular. Conversely, active sleep (AS), which approximates to rapid eye movement (REM) sleep, was defined by periods in which there were more frequent movements of the body and extremities, facial grimaces, rapid eye movements and irregular breathing.

Data analysis. Each individual sleep study was analysed using CARDAS: an interactive computerized program. Periods of artefactual signals were excluded by visual inspection of the raw data signals and by reference to the video record and observer's notes. In addition to the observation of movements on the video record, periods in which the pulse wave signals (from the pulse oximeter) were of poor quality and those in which changes in pulse rate were not matched by changes in cardiac frequency $(f \mathrm{C}$; measured by ECG) were excluded. Mean and SD values for $\mathrm{Sa}_{\mathrm{a}} \mathrm{O}_{2}$ and $f \mathrm{C}$ were calculated for each behavioural sleep state. The patterns of the recorded signals themselves were ana- lysed in 3 min epochs in order to allow the observation of isolated oscillations in all signals, visualization of individual breaths and identification of both central and obstructive respiratory anomalies. These were defined as:

1) Central respiratory pauses: cessation of respiratory movements, observed in both rib cage and abdominal signals. These pauses were described in terms of their frequency (number per hour of sleep), duration (in seconds), and their impact on $\mathrm{Sa}_{\mathrm{a}} \mathrm{O}_{2}$ (number of dips in $\mathrm{Sa}, \mathrm{O}_{2}$ greater than $4 \%$ per hour of sleep ( $>4 \% \mathrm{Sa}_{2} \mathrm{O}_{2}$ dip rate), the lowest $\mathrm{Sa}, \mathrm{O}_{2}$ values consequent to the respiratory pause $\left(\mathrm{Sa}_{\mathrm{a}} \mathrm{O}_{2}, \mathrm{~min}\right)$ and the percentage of sleep time spent with $\mathrm{Sa}_{\mathrm{a}} \mathrm{O}_{2}$ below $92 \%\left(\mathrm{Sa}, \mathrm{O}_{2},<92 \%\right)$.

2) Upper airway obstruction: the presence and the severity of the obstructive breathing problems were diagnosed by using a combination of clinical and polygraphic criteria (table 2). Inspection of the polygraphic data was used to define the relationship between rib cage and abdominal signals (which varied between the completely synchronous and the completely paradoxical), and the extent of change in $\mathrm{Sa}, \mathrm{O}_{2}$ caused by the periods of obstruction ( $>4 \%$ $\mathrm{Sa}_{\mathrm{a}, \mathrm{O}_{2}}$ dip rate, $\mathrm{Sa}_{\mathrm{a}} \mathrm{O}_{2}, \mathrm{~min}$, and $\mathrm{Sa}_{\mathrm{a}} \mathrm{O}_{2},<92 \%$ ).

3) Mixed apnoeas were defined as periods during which both central and obstructive apnoeic components were evident. The order of the sequence of obstructive efforts and central respiratory pauses was not taken into account. The effects on $\mathrm{Sa}_{\mathrm{a}} \mathrm{O}_{2}$ were measured as above $\left(>4 \% \mathrm{Sa}, \mathrm{O}_{2}\right.$ dip rate, $\mathrm{Sa}, \mathrm{O}_{2}, \mathrm{~min}$, and $\mathrm{Sa}, \mathrm{O}_{2},<92 \%$ ).

Group analysis: both $\mathrm{Sa}_{2} \mathrm{O}_{2}$ and the $f \mathrm{C}$ were recorded at a frequency of $1 \mathrm{~Hz}$. Using an interactive computerized analysis, in which the periods of QS and AS were determined on the basis of the behavioural criteria (see above), the overall mean and SD values for $S_{\mathrm{a}} \mathrm{O}_{2}$ and $f \mathrm{C}$ for each sleep state were calculated.

\section{Results}

Over the course of the study there were no patients who needed to be excluded or have their sleep study postponed because of acute respiratory problems.

\section{Clinical history}

Details of the classification of respiratory problems, based upon the clinical history, are given in table 3 . Based upon parents' descriptions, none of the patients had a clinical history suggestive of central respiratory problems. However, in seven of 13 cases the children were described by their parents as having symptoms associated with some degree of upper airway obstruction during sleep. On the basis of the parents' observations, two children were classified as mild, three as moderate and two as severe (table 3 ). Of the six children whose parents denied respiratory problems, two had tracheostomies and four were apparently well.

\section{Hindbrain herniation}

The extent of hindbrain herniation ranged 1.5-27 mm (median $9.5 \mathrm{~mm}$ ). Details are given in table 1 . 
Table 3. - History of respiratory problems based upon parents' descriptions and summary of sleep study data from arterial oxygen saturation $\left(\mathrm{S}, \mathrm{O}_{2}\right)$ and cardiac frequency $(f \mathrm{c})$ for individual patients

\begin{tabular}{|c|c|c|c|c|c|c|}
\hline \multirow[t]{2}{*}{$\begin{array}{l}\text { Patient } \\
\text { No. }\end{array}$} & \multicolumn{2}{|c|}{$\begin{array}{l}\text { Assessment of respiratory problems } \\
\text { based on clinical history from parents }\end{array}$} & \multicolumn{2}{|c|}{$\mathrm{Sa}_{\mathrm{a}, \mathrm{O}_{2}} \%$} & \multicolumn{2}{|c|}{$f \mathrm{C}$ beats $\cdot \mathrm{min}^{-1}$} \\
\hline & Central & Obstructive & QS & AS & QS & AS \\
\hline 1 & None & None & $95.1(0.6)$ & $94.6(1.2)$ & $113.9(4.1)$ & $109.6(8.4)$ \\
\hline 2 & None & None & $96.7(0.3)$ & $97.2(0.7)$ & $68.9(3.8)$ & $70.2(5.9)$ \\
\hline 3 & None & Moderate & $94.7(1.0)$ & $94.4(1.8)$ & $128.6(4.1)$ & $133.9(7.8)$ \\
\hline 4 & None & Severe & $93.8(4.4)$ & 83.7 (11.7) & $119.0(10.3)$ & $120.8(12.4)$ \\
\hline 5 & None & Mild & $98.3(0.6)$ & $98.3(0.9)$ & $116.2(4.7)$ & $121.3(6.7)$ \\
\hline 6 & None & Moderate & $96.7(1.0)$ & $96.8(1.7)$ & $84.8(3.9)$ & $91.9(6.1)$ \\
\hline 7 & None & Moderate & $93.4(1.7)$ & $88.4(8.1)$ & $92.8(6.6)$ & $88.0(11.7)$ \\
\hline 8 & None & None & $96.5(0.7)$ & $95.8(1.1)$ & $83.0(4.8)$ & $85.7(7.2)$ \\
\hline 9 & None & Mild & $95.2(0.8)$ & $94.1(1.8)$ & $106.5(6.3)$ & $107.6(6.1)$ \\
\hline 10 & None & None (tracheostomy) & $95.8(0.8)$ & $96.2(0.6)$ & $63.7(4.4)$ & $70.9(7.8)$ \\
\hline 11 & None & Severe & $90.5(2.0)$ & $87.4(7.0)$ & $163.8(11.2)$ & $157.6(14.9)$ \\
\hline 12 & None & None (tracheostomy) & $95.7(1.0)$ & $96.6(0.8)$ & $76.1(4.3)$ & $82.5(5.8)$ \\
\hline 13 & None & None & $95.6(1.5)$ & $93.2(1.7)$ & $86.9(9.4)$ & $83.2(8.0)$ \\
\hline Group & & & $95.4(2.0)$ & $93.9(4.4)$ & $101.6(27.3)$ & $103.2(25.7)$ \\
\hline
\end{tabular}

Values are presented as mean, and SD in parenthesis. QS: quiet sleep; AS: active sleep.

Table 4. - Summary data for central apnoeas, upper airway obstruction and mixed apnoeas in all 13 patients.

\begin{tabular}{|c|c|c|c|c|c|c|c|c|c|c|c|c|c|}
\hline \multirow[b]{2}{*}{$\begin{array}{l}\mathrm{Pt} \\
\text { No. }\end{array}$} & \multicolumn{5}{|c|}{ Central apnoeas } & \multicolumn{4}{|c|}{ Upper airway obstruction } & \multicolumn{4}{|c|}{ Mixed apnoeas } \\
\hline & $f^{+}$ & $\begin{array}{c}\text { Dur. } \\
\mathrm{s}\end{array}$ & $\begin{array}{c}4 \% \\
\text { dips } \\
\text { dips } \cdot h^{-1}\end{array}$ & $\begin{array}{c}\mathrm{S}_{\mathrm{a}, \mathrm{O}_{2}} \\
<92 \% \\
\% \text { sleep }\end{array}$ & $\underset{\%}{\operatorname{Min}}$ & Sev. & $\begin{array}{c}>4 \% \\
\text { dips } \\
\text { dips } \cdot h^{-1}\end{array}$ & $\begin{array}{c}\mathrm{S}_{\mathrm{a}, \mathrm{O}_{2}} \\
<92 \% \\
\% \text { sleep }\end{array}$ & $\underset{\%}{\operatorname{Min}}$ & $f^{+}$ & $\begin{array}{c} \\
>4 \% \\
\text { dips } \\
\text { dips } h^{-1}\end{array}$ & $\begin{array}{l}\mathrm{S}_{\mathrm{a}, \mathrm{O}_{2}} \\
<92 \% \\
\% \text { sleep }\end{array}$ & $\underset{\%}{\operatorname{Min}}$ \\
\hline 1 & 9.3 & $4-13$ & 0 & 0 & 92 & Mild & 1.9 & 0.6 & 83 & 0.7 & 1.0 & 0 & 89 \\
\hline 2 & 4.6 & $3-7$ & 0 & 0 & 95 & Absent & - & - & - & 0 & - & - & - \\
\hline 3 & 9.8 & $3-5$ & 0 & 0 & 93 & Mod. & 18.2 & 6.2 & 83 & 3.4 & 2.1 & 0.8 & 82 \\
\hline 4 & 1.4 & $3-11$ & 0.4 & 0.1 & 87 & Severe & 60.6 & 52.7 & 18 & 13.6 & 11.2 & 6.5 & 60 \\
\hline 5 & 6.4 & $3-12$ & 0.3 & 0 & 94 & Mild & 1.3 & 0 & 92 & 0.3 & 0.3 & 0 & 92 \\
\hline 6 & 27.2 & $3-12$ & 4.8 & 0.7 & 86 & Mild & 0 & 0 & 91 & 0 & - & - & - \\
\hline 7 & 0 & - & - & - & - & Severe & 21.6 & 29.0 & 60 & 0 & _ & - & - \\
\hline 8 & 3.2 & $4-11$ & 0 & 0 & 93 & Mild & 0.3 & 0 & 91 & 0 & - & - & - \\
\hline 9 & 6.1 & $3-7$ & 0 & 0 & 93 & Mod. & 3.3 & 2.8 & 88 & 1.02 & 0.4 & 0.4 & 87 \\
\hline 10 & 4.7 & $3-10$ & 0 & 0 & 92 & Absent & - & - & - & 0 & - & - & - \\
\hline 11 & 0 & - & - & & - & Severe & 28.6 & 70.5 & 61 & 0 & - & - & - \\
\hline 12 & 5.6 & $5-10$ & 0.3 & 0 & 92 & Absent & - & - & - & 0 & _ & - & - \\
\hline 13 & 1.6 & $7-11$ & 0 & 0 & 93 & Mod. & 13.4 & 7.0 & 88 & 0 & - & - & - \\
\hline Group* & $\begin{array}{c}6.2 \\
(7.1)\end{array}$ & & $\begin{array}{r}0.5 \\
(1.4)\end{array}$ & $\begin{array}{r}0.1 \\
(0.2)\end{array}$ & $\begin{array}{c}91.8 \\
(2.8)\end{array}$ & & $\begin{array}{c}14.9 \\
(19.0)\end{array}$ & $\begin{array}{r}16.9 \\
(25.5)\end{array}$ & $\begin{array}{c}75.5 \\
(23.4)\end{array}$ & $\begin{array}{c}1.5 \\
(3.8)\end{array}$ & $\begin{array}{c}3.0 \\
(4.6)\end{array}$ & $\begin{array}{c}1.5 \\
(2.8)\end{array}$ & $\begin{array}{c}82.0 \\
(12.8)\end{array}$ \\
\hline
\end{tabular}

Central apnoeas are described in terms of the frequency of periods of cessation of respiratory movements per hour of sleep, the duration of the pauses and the subsequent effect on arterial oxygen saturation $\left(\mathrm{Sa}_{\mathrm{a}} \mathrm{O}_{2}\right)$ in terms of the number of $>4 \%$ dips in $\mathrm{Sa}_{\mathrm{a}} \mathrm{O}_{2}$ per hour of sleep, percentage of total sleep time with $\mathrm{Sa}_{\mathrm{a}} \mathrm{O}_{2}<92 \%$ and the minimum (Min) $\mathrm{Sa}, \mathrm{O}_{2}$ achieved. Episodes of upper airway obstruction are classified in terms of their severity score based upon clinical observation and sleep study data (table 2), and the subsequent impact on $\mathrm{Sa}_{\mathrm{a}} \mathrm{O}_{2}$. Mixed apnoeas are described by their frequency per hour of sleep, and by their effect on $\mathrm{Sa}_{\mathrm{a}, \mathrm{O}_{2}}$. The dashes (-) are used to indicate absence of a specific type of apnoea in an individual. +: measured in units of apnoeas $\cdot \mathrm{h}^{-1}$; *: mean (SD). Pt: patient; $f$ : frequency; Dur.: duration; Sev.: severity; Mod.: moderate.

\section{Respiratory patterns during sleep}

The results of the analysis of breathing patterns during sleep for each patient are summarized in table 4. The impact of the different types of apnoeas on $\mathrm{Sa}_{\mathrm{a}} \mathrm{O}_{2}$ for the group as a whole, in relation to the sleep state, are shown in figure 2. In general, apnoeic events of all types tended to be more frequent and more severe during active sleep.

Central respiratory pauses (table 4). Isolated, intermittent respiratory pauses ranging $3-13 \mathrm{~s}$ in duration were observed in 11 of 13 cases, with frequencies ranging 1.4-27.2 apnoeas $\cdot \mathrm{h}^{-1}$ of sleep. In four individuals central respiratory pauses were associated with dips in $\mathrm{Sa}_{2} \mathrm{O}_{2}$ in excess of $4 \%$, but in only two of them did $\mathrm{Sa}_{\mathrm{a}} \mathrm{O}_{2}$ fall below $92 \%$ as a consequence of a central apnoea. Overall, central apnoeas caused $\mathrm{S}_{\mathrm{a}, \mathrm{O}_{2}}$ to fall below $92 \%$ for less than $1 \%$ of the total sleep time, reaching a minimum value of $86 \%$ in patient No. 6.

Obstructive events (table 4). In 10 of 13 children some degree of upper airway obstruction during sleep was observed, whilst two of three remaining children, in whom breathing patterns were considered normal, already had tracheostomies. The severity of the obstruction in the 10 cases identified was classified as mild in four cases, moderate in three, and severe in three. In nine individuals there were dips in $\mathrm{Sa}_{\mathrm{a}} \mathrm{O}_{2}$ in excess of $4 \%$, with the lowest recorded levels ranging 18-92\%. Seven children had $\mathrm{Sa}_{\mathrm{a}} \mathrm{O}_{2}$ levels below $92 \%$ for $0.6-70.5 \%$ of total sleep time. The $>4 \% \mathrm{Sa}, \mathrm{O}_{2}$ dip rate, $\mathrm{Sa}, \mathrm{O}_{2},<92 \%$ time and the $\mathrm{Sa}, \mathrm{O}_{2}$, min were all proportional to the severity of the obstruction, based upon clinical observation and global analysis of the sleep study data. 

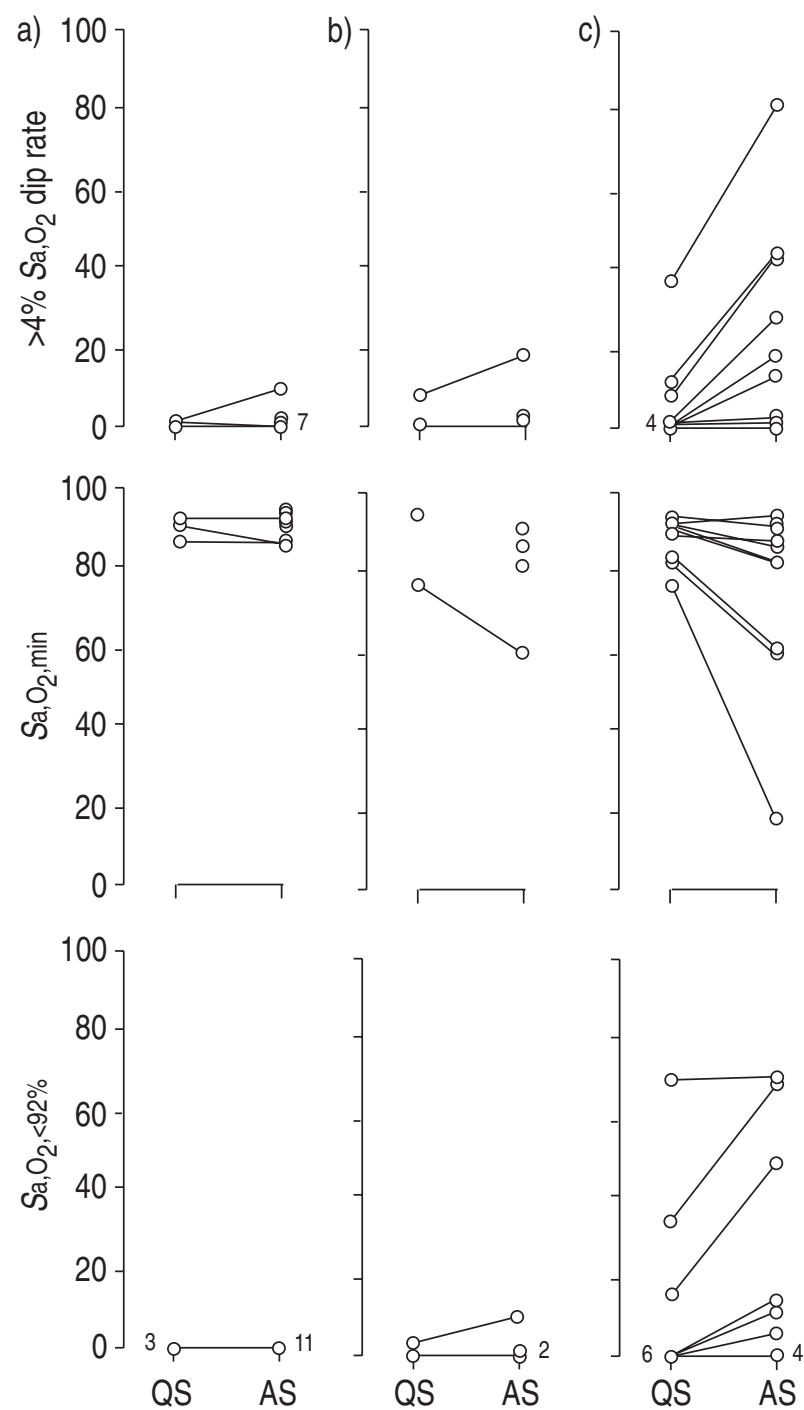

Fig. 2. - Effect of a) central apnoea ( $n=11$ patients; $Q S=3, A S=11), b)$ mixed apnoeas $(n=5$ patients; $Q S=2, A S=4)$ and $c)$ obstructive apnoea $(\mathrm{n}=10$ patients; $\mathrm{QS}=9, \mathrm{AS}=10)$ upon arterial oxygen saturation $\left(\mathrm{Sa}_{\mathrm{a}} \mathrm{O}_{2}\right)$ according to the sleep state. The changes in $\mathrm{Sa}_{\mathrm{a}} \mathrm{O}_{2}$ are expressed as the number of dips greater than $4 \%$ per hour ( $>4 \% \mathrm{Sa}_{\mathrm{a}, \mathrm{O}_{2}}$ dip rate), percentage of total sleep time with $\mathrm{Sa}_{\mathrm{a}} \mathrm{O}_{2}<92 \%\left(\mathrm{~S}_{\left.\mathrm{a}, \mathrm{O}_{2},<92 \%\right)}\right.$ and the minimum $\mathrm{Sa}_{\mathrm{a}, \mathrm{O}_{2}}\left(\mathrm{Sa}, \mathrm{O}_{2}, \mathrm{~min}\right)$ achieved. Pairs of points that are joined by lines represent individuals who had events in both QS and AS. Isolated points correspond to patients in whom events occurred in either QS or AS. The numbers adjacent to the abscissa represent the number of coincident zero values. QS: quiet sleep; AS: active sleep.

Mixed apnoeas (table 4). Mixed apnoeas were observed in five of 13 children, all of whom also had isolated intermittent respiratory pauses and isolated obstructive episodes. The degree of obstruction was scaled as mild in two cases, moderate in two cases and severe in one case. In all instances of mixed apnoeas, the obstructive component preceded the central apnoea. Four cases were associated with significant changes in $\mathrm{Sa}_{\mathrm{a}} \mathrm{O}_{2}$, all of whom had a degree of obstruction that was sufficient to cause marked arterial oxygen desaturation in its own right. In only one child with mixed apnoeas (No. 4) did central apnoeas in isolation lead to significant falls in $\mathrm{Sa}_{\mathrm{a}} \mathrm{O}_{2}$. The magnitude of the changes in $\mathrm{Sa}_{2} \mathrm{O}_{2}$ was always related to the severity of the obstructive problem.

\section{Discussion}

The results of the present study revealed both central and obstructive episodes of varying severity during sleep in a group of children with craniofacial dysostoses associated with hindbrain herniation. However, contrary to expectations, there was only a low level of central and/or mixed apnoea types during sleep. The predominant sleeprelated respiratory problem identified in these patients was obstruction of the upper airways, which is in accordance with the results of earlier studies in craniofacial patients in whom hindbrain herniation was not necessarily present $[9,11]$.

From the literature, the frequency of sleep-related breathing problems in normal children and adolescents is low and arterial oxygen desaturations are unusual [12-15]. In terms of normal values, median overnight saturation levels have been described as maintained at $95 \%$ (5th to 95th centile $=92-97 \%$ ), with a median of one dip $>4 \%$ per hour of sleep (5th to 95th centile $=0-2.8$ ) [13]. Taking into account mean $\mathrm{Sa}, \mathrm{O}_{2}$ alone, the present group of patients had only three children with abnormal mean values, when compared to the normal population. However, the use of mean levels of $\mathrm{Sa}_{\mathrm{a}} \mathrm{O}_{2}$ alone may be misleading. When other $\mathrm{Sa}, \mathrm{O}_{2}$-related parameters (the amount of time spent with $\mathrm{Sa}, \mathrm{O}_{2},<92 \%$, the number of dips in $\mathrm{Sa}_{\mathrm{a}} \mathrm{O}_{2}$ greater than $4 \%$ and the lowest $\mathrm{Sa}_{\mathrm{a}} \mathrm{O}_{2}$ levels) were used to complement the analysis of $\mathrm{Sa}_{\mathrm{a}} \mathrm{O}_{2}$, abnormalities were observed in eight children.

In relation to the breathing patterns of normal children, central respiratory pauses with no clinical consequences have also been observed during sleep $[12,14]$ and a number of authors, studying different paediatric age groups, have reported the mean duration of the longest pauses ranging 8-12 s [16, 17], with isolated apnoeas reaching up to $25 \mathrm{~s}$ [18]. The clinical significance of short apnoeas is not clear, and they are usually considered important only if associated with bradycardia or hypoxaemia [12]. In comparison to these data for normal children, only two of 13 of our patients (Nos. 4 and 6) had significant desaturations associated with central respiratory pauses. Moreover, the dips were not severe, and corresponded to less than $1 \%$ of the total sleep time. In the remaining 11 of 13 children, the frequency of pauses and the severity of their consequences were similar to those reported for the normal paediatric population. In contrast, upper airway obstruction was seen in 10 of 13 individuals, and mixed apnoeas in five of 13, all of which can be considered abnormal, since both mixed and obstructive apnoeas are expected to be absent in normal children [18].

The present study was designed to describe the breathing patterns during sleep in a group of craniofacial patients with hindbrain herniation, and as such it does not allow us to make conclusions about the mechanisms that could possibly explain the respiratory abnormalities that have been observed. Whilst the baseline anatomical abnormalities alone could be responsible for the obstructive patterns [9], on the basis of this study one could not exclude the possibility of the contribution of central respiratory control disorders leading to impairment of cranial nerve function and resulting in secondary obstruction. Further studies to look at cranial nerve function and upper airway reflexes are indicated in these patients to answer this question. 
It would have been interesting to have been able to distinguish the degree of obstructive apnoea/hypopnoea on the basis of measurements of respiratory flow. However, for a number of reasons these measurements were not feasible in this group of patients. Firstly, because of their age (most were aged $<7 \mathrm{yrs}$ ) there was poor collaboration by the patients with sleep study procedures. In addition, most of the patients had some degree of developmental delay. Furthermore, as they were studied during natural sleep, without sedation, measurements from near the face were deemed impossible. For this reason, we were limited to describing periods of obstruction of the upper airways, without distinguishing between partial and complete obstruction. Nevertheless, the impact of the obstructive episodes on both $\mathrm{Sa}_{\mathrm{a}} \mathrm{O}_{2}$ and $f \mathrm{C}$ could be used as a measure of the severity of the obstructive episodes.

We used $\mathrm{Sa}_{\mathrm{a}} \mathrm{O}_{2}$ as the primary quantitative measurement of the severity of the breathing impairment in the present patients. However, it should also be emphasized that the sleep studies included a variety of polygraphic data, of which $\mathrm{Sa}_{\mathrm{a}} \mathrm{O}_{2}$ was only one component, as well as clinical observations made by an experienced observer. The use of $\mathrm{Sa}, \mathrm{O}_{2}$ alone has limitations, particularly as an index of the severity of upper airway obstruction. In some individuals with significant obstruction, $\mathrm{Sa}, \mathrm{O}_{2}$ may still be maintained at the expense of markedly increased breathing efforts. Furthermore, the characteristic obstructive pattern, with recurrent arousals, leads to an oscillating pattern of $\mathrm{Sa}, \mathrm{O}_{2}$, the severity of which tends to be poorly reflected by the mean $\mathrm{Sa}_{2} \mathrm{O}_{2}$ values. Because of these limitations in mean $\mathrm{Sa}_{\mathrm{a}} \mathrm{O}_{2}$ values, we described the severity of the changes in $\mathrm{Sa}_{\mathrm{a}} \mathrm{O}_{2}$ in terms of the number of dips in $\mathrm{Sa}, \mathrm{O}_{2}$ greater than $4 \%$ and the lowest level of $\mathrm{Sa}_{2} \mathrm{O}_{2}$ observed during the sleep study [15], and we also quoted the amount of time spent with $\mathrm{Sa}, \mathrm{O}_{2}$ below $92 \%$ for each individual [12].

In the present study, we defined hindbrain herniation as any descent of the cerebellar tonsils below the plane of the foramen magnum, and in all cases it corresponded to the type I Chiari malformation. The literature on the respiratory consequences of hindbrain herniation is almost exclusively based on the study of cases of the Arnold-Chiari or Chiari II malformation. However, as the type II malformation may involve other anatomical anomalies of the central nervous system, interpretation of these results in terms of the effects of an isolated hindbrain herniation is complicated. Nevertheless, a number of cases of Chiari types I and II malformations have been described in association with a variety of respiratory abnormalities, including: 1) central sleep apnoea and respiratory control disorders, attributed to compression/traction of the brainstem, or vascular effects upon the chemoreceptors of the medulla [8]; 2) hypoventilation, due to cord compression [8];3) persistent cyanosis, caused by microatelectasis secondary to persistent low lung volumes [8]; 4) breath-holding spells, resulting from decreased ventilatory sensitivity to hypercapnia and hypoxia [8]; 5) diaphragmatic paralysis, as a consequence of compression of the phrenic nerve [19]; 6) impaired peripheral chemosensitivity, due to impairment of peripheral chemoreceptor afferents, secondary to dysfunction of the ninth (glossopharyngeal) cranial nerve [20]; and 7) upper airway obstructive problems, resulting from the involvement of cranial nerves (IX-XII pairs), with consequent collapse of the tongue, posterior pharynx or vocal cords. The clinical manifestations associated with this include stridor (when there is bilateral vocal cord paralysis), feeding and swallowing difficulties, aspiration and obstructive apnoea [8].

The absence of any significant bradycardias in our patients suggests that brainstem cardiac regulation was not noticeably affected by their tonsillar herniation. Nevertheless, the patients with obstructive problems demonstrated a marked variability in $f \mathrm{C}$, associated with their respiratory efforts, a characteristic of obstructive sleep apnoea, and peaks of increased $f \mathrm{C}$ associated with arousals from obstructive episodes [20].

Although the present study did not include an examination for abnormalities of the airways below the pharynx and none of our patients had stridor or other symptoms of lower respiratory impairment on examination, all moderate and severe cases of upper airway obstruction during sleep were subsequently found to improve with treatment involving only the upper airways. Whilst it was felt unnecessary to treat cases with mild upper airway obstruction, both moderate and severe cases have since been treated with either a nasopharyngeal airway, nasal continuous positive airway pressure (CPAP) or, in one case (No. 4), a tracheostomy. Early indications suggest that the clinical response to treatment of the upper airway obstruction was excellent in all patients, with improvement of the obstruction itself, resumption of a restful sleep pattern and better weight gain. Two of the patients already had long-term tracheostomies before they were included in the study. They had the more sizeable herniations of the hindbrain, when compared to the others, and the presence of the tracheostomy allowed us to observe any central respiratory abnormalities in the absence of upper airway obstructive problems. Interestingly, both had infrequent episodes of short central apnoeas, which did not affect either $\mathrm{Sa}_{\mathrm{a}} \mathrm{O}_{2}$ or $f \mathrm{C}$.

In a previous report, we observed that upper airway obstructive problems are frequent in children with craniofacial dysostoses [9]. The present study confirms these findings and demonstrates how, even when hindbrain herniation is present, obstruction of the upper airways is still the most important feature. These findings have implications for the treatment of breathing problems in this group of children. It is also important to remember that, because of the complexity of the multiple problems posed by these patients, mild to moderate sleep-related respiratory obstructions may not be reported by the parents. This has important implications when assessing anaesthetic risk for these children. It can also contribute to such apparently unrelated problems as failure to thrive and the many consequences of sleep deprivation.

Acknowledgements: The authors would like to thank J. Stocks and D. Hatch for their guidance. They also thank S. Brown, of the Dept of Medical Illustration of the Great Ormond Street Hospital for Children and The Institute of Child Health NHS Trust, for his help.

\section{References}

1. Marchac D, Renier D. Craniosynostosis. World J Surg 1989; 13: 358-365.

2. Saldino RM, Steinbach HL, Epstein CJ. Familial acrocephalosyndactyly (Pfeiffer syndrome). Am J Roentgenol Radium Ther Nucl Med 1972; 116: 609-622. 
3. Venes JL. Arnold-Chiari malformation in an infant with Kleeblattschädel: an acquired malformation? Neurosurgery 1988; 23: 360-362.

4. Francis PM, Beals S, Rekate HL, Pittman HW, Manwaring K, Reiff J. Chronic tonsillar herniation and Crouzon's syndrome. Pediatr Neurosurg 1992; 18: 202-206.

5. Thompson D, Gonsalez S, Lane R, Jones B, Harkness W, Hayward R. Chronic tonsillar herniation in craniosynostosis - causes and effects. (Abstract). Child's Nerv Syst 1994; 10: 411

6. Cinalli G, Renier D, Marchac D, Sainte-Rose C, Arnaud E, Pierre-Kahn A. Chiari malformation in craniofacial premature synostosis. (Abstract). Child's Nerv Syst 1994; 10 : 411.

7. Cinalli G, Renier D, Sebag G, Sainte-Rose C, Arnaud E, Pierre-Kahn A. Chronic tonsillar herniation in Crouzon's and Apert's syndromes: the role of premature synostosis of the lambdoid suture. J Neurosurg 1995; 83: 575-582.

8. Nickerson B. Control of breathing problems associated with Arnold-Chiari malformation. In: Beckerman RC, Brouillette RT, Hunt CE, eds. Respiratory Control Disorders in Infants and Children. Baltimore, Williams and Wilkins, 1992; pp. 271-276.

9. Gonsalez SL, Hayward R, Jones B, Lane R. Upper airway obstruction and raised intracranial pressure in children with craniosynostosis. Eur Respir J 1997; 10: 367-375.

10. Prechtl HFR. The behavioural states of the newborn infant (a review). Brain Res 1974; 76: 185-212.

11. Mixter RC, David DJ, Perloff WH, Green CG, Pauli RM, Popic PM. Obstructive sleep apnea in Apert's and Pfeiffer's syndromes: more than a craniofacial abnormality. Plast Reconstr Surg 1990; 86: 457-463.

12. Brouillette RT. Assessing cardiopulmonary function dur- ing sleep in infants and children. In: Beckerman RC, Brouillette RT, Hunt CE, eds. Respiratory control disorders in infants and children. Baltimore, Williams and Wilkins, 1992; pp. 125-141.

13. Guilleminault C, Ariagno R. Apnea during sleep in infants and children. In: Kryger MH, Roth T, Dement WC, eds. Principles and Practice of Sleep Medicine. Philadelphia, WB Saunders Company, 1989; pp. 655-664.

14. Sheldon SH, Spire J-P, Levy H. Sleep-disordered respiration in childhood. In: Pediatric Sleep Medicine. Philadelphia, WB Saunders Company, 1992; pp. 136-150.

15. Stradling JR, Thomas G, Warley ARH, Williams P Freeland A. Effect of adeno-tonsillectomy on nocturnal hypoxaemia, sleep disturbance and symptoms in snoring children. Lancet 1990; 335: 249-253.

16. Hunt CE, Brouillette RT, Hanson D, David RJ, Stein IM, Weissbluth M. Home pneumograms in normal infants. $J$ Pediatr 1985; 106: 551-555.

17. Richards JM, Alexander JR, Shinebourne EA, Swiet MM, Wilson AJ, Southall DP. Sequential 22-hour profiles of breathing patterns and heart rate in 110 full-term infants during their first 6 months of life. Pediatrics 1984; 74: 763-767.

18. Carskadon MA, Harvey K, Dement WC, Guilleminault C, Simmons FB, Anders TF. Respiration during sleep in children. West J Med 1978; pp. 477-481.

19. Montserrat JM, Picado C, Agustí-Vidal A. Arnold-Chiari malformation and paralysis of the diaphragm. Respiration 1988; 53: 128-131.

20. Stradling JR. Pathophysiology of obstructive sleep apnoea. In: Handbook of Sleep-Related Breathing Disorders. 1st Ed. Oxford, Oxford University Press, 1993; pp. 23-64. 